evoked oto-acoustic emissions. Arch Otolaryngol Head Neck Surg 1988:114 $887-90$

9 Jacobson JT, Morehouse CR. A comparison of auditory brain stem response and behavioural screening in high risk and normal newborn infants. Ear Hear 1984:5:247-53.

10 Mahoney TM, Eichwald JG. The ups and "downs" of high risk screening: the Utah statewide program. Seminars in Hearing 1987;8:155-63.

11 Stein L, Clark S, Kraus N. The hearing impaired infant: patterns of identification and habilitation. Ear Hear 1983;4:232-6.

12 Elssmann SF, Matkin ND, Sabo MP. Early identification of sensorineural hearing impairment. The Hearing fournal 1987;40:13-7.
13 American Speech-Hearing-Language Association. Guidelines for the identification of hearing impairment in at risk infants age birth to 6 months. ASHA 1988:30:61-4.

14 Hendricks-Munoz KD, Walton JP. Hearing loss in infants with persistent fetal circulation. Pediatrics 1988;81:650-6.

15 Naulty CM, Weiss IP, Herer GR. Progressive sensorineural hearing loss in survivors of persistent fetal circulation. Ear Hear 1986;7:74-7.

16 Hall DMB, ed. Screening for hearing impairment. In: Health for all children. Oxford: Oxford Medical Publications, 1989:59-67.

(Accepted 24 August 1990)

\section{Catheterisation: your urethra in their hands}

\author{
R Carter, M Aitchison, G R Mufti, R Scott
}

Department of Urology, Glasgow Royal Infirmary, Glasgow G4 OSF R Carter, FRCS, registrar M Aitchison, FRCS, senior registrar

G R Mufti, FRCS, consultant urologist

R Scott, FRCS, consultant urologist

Correspondence to: Mr Carter.

$\operatorname{BrMed~f~1990;301:90~}$ from one junior to the next.' The philosophy is of "See officers.
The emphasis in undergraduate medical education is often on the theoretical aspects of medicine rather than the practical aspects. Practical procedures are commonly taught informally, the teaching being passed one, do one, teach one." Urethral catheterisation is a procedure that requires a certain amount of skill, knowledge, and experience and is not without complication,,$^{2-4}$ yet it is usually delegated to the most junior and inexperienced medical staff, the junior house

\section{Subjects, methods, and results}

To assess the level of competence at catheterisation among junior medical staff house officers at this hospital were interviewed with a structured questionnaire, covering three aspects of the procedure: the degree of undergraduate and postgraduate instruction, the practical and theoretical aspects of catheterisation, and, finally, problems and complications encountered.

Thirty junior house officers (graduates of five medical schools) were interviewed. Eighteen were male and 12 were female. The replies to the questionnaire showed that none of the interviewees had received any formal instruction regarding any aspect of urethral catheterisation as an undergraduate. Practical postgraduate instruction in 24 was limited to supervision of a single catheterisation, and four subjects were unsupervised. Although those interviewed had performed a mean of 28 (range 6-100) catheterisations in female patients.

Despite the large number of procedures performed there was appreciable ignorance of the practical and theoretical aspects of catheterisation. Twenty five interviewees were unaware of the availability of short term and long term catheters or of the duration for male patients, only four of them had catheterised which they may be safely left without being changed. Three interviewees simply used the catheter that was provided by the nursing staff, and one did not know that different sizes existed.

Twenty eight interviewees initially used force when meeting resistance to the passage of the catheter, and 13 stated that the development of fresh urethral bleeding would not deter them from a further attempt at catheterisation. Eighteen were happy to attempt catheterisation in a patient who had a known urethral stricture. Five interviewees were unaware of the difference between a phimosis and paraphimosis.

Despite the lack of formal tuition all had developed what seemed to be a satisfactory aseptic technique. None, however, was aware of the nature of the antiseptic fluid or the strength of the local anaesthetic gel, but simply used what was provided by the nursing staff

Nineteen of the interviewees had encountered bleeding and six had had patients in whom a paraphimosis had developed after catheterisation. A particularly disturbing finding was that, although 14 interviewees had requested help from senior medical staff, seven were reluctant to seek advice, because of their impression that difficulties with catheterisation were not worthy of disturbing senior staff. Eight of the 12 female medical staff had encountered problems with male patients becoming sexually excited during the procedure.

\section{Discussion}

The results of our survey suggest that the technique of urethral catheterisation is poorly taught, and in the light of these results we are preparing a short teaching video to be shown to every house officer at the start of their preregistration post.

1 Royal College of Physicians. Resuscitation from cardiopulmonary arrest. Training and organisation. London: RCP, 1987 . 1987;19:109-11.

3 Merguerian PA, Erturk E, Hulbert WC, et al. Peritonitis and abdominal free air due to intraperitoneal bladder perforation associated with indwelling urethra catheter drainage. $\mathcal{F}$ Urol 1985;134:747-50.

4 Macfarlane DE. Prevention and treatment of catheter-associated urinary tract infections. F Infect 1985;10:96-106.

(Accepted 8 August 1990)

induce vaginal oestrus in laboratory animals ${ }^{4}$ in postmenopausal women not taking oestrogen replacement therapy.

$$
\text { II }
$$

\section{Subjects, methods, and results}

We studied 25 postmenopausal women who were non-smokers, in good general health, and taking no drugs known to affect oestrogen state (mean age 59 (range 51-70); body mass index $24 \cdot 4$ (range 18.7-31.6) $\mathrm{kg} / \mathrm{m}^{2}$; years after menopause $8 \cdot 1$ (range $\left.1-20\right)$ ). The protocol was a latin square design with a two week run in period and a six week experimental period. The women recorded their normal diet for 14 days and were asked to repeat the fortnightly diet throughout the study. During the experimental period the diet was
2 Blandy JP. Emergency situations. Acute retention of urine. Br f Hosp Med acid lactones, ${ }^{2}$ which may be activated or inactivated. We studied the effect of three foods reported to

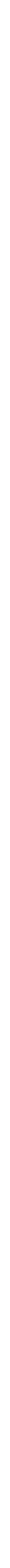

Crops grown as animal pasture are known to oestrogenic activity, ${ }^{1}$ and some foods contain potential oestrogenic analogues such as the isoflavonoids (isoflavones and coumestans), lignans, and resorcyclic 